\title{
Micro-Raman study of nanocomposite porous films with silver nanoparticles prepared using pulsed laser deposition
}

\author{
V.V. Strelchuk, O.F. Kolomys, B.O. Golichenko, M.I. Boyko, E.B. Kaganovich, I.M. Krishchenko, \\ S.O. Kravchenko, O.S. Lytvyn, E.G. Manoilov, Iu.M. Nasieka \\ V. Lashkaryov Institute of Semiconductor Physics, NAS of Ukraine, \\ 41, prospect. Nauky,03028 Kyiv, Ukraine, e-mail: dept_5@isp.kiev.ua
}

\begin{abstract}
Nanocomposite porous films with silver nanoparticle (Ag NP) arrays were prepared by the pulsed laser deposition from the back flux of erosion torch particles in argon atmosphere on the substrate placed at the target plane. Preparation conditions of the films were set by argon pressure, energy density of laser pulses, their amount and substrate position relatively to the torch axis. The films were prepared with gradient thickness, variable Ag NP sizes and distance between them along the length of substrate as well as corresponding maxima in the spectra of local surface plasmon absorption. Plasmon effects of the Raman scattering enhance in the matter of the Ag NP shell gave the opportunity to register the spectral bands caused by an extremely small quantity of silver compounds with oxygen and carbon. The possible nature of individual bands in the Raman spectrum was analyzed. The obtained results are important for interpretation of the Raman spectra of analytes based on the prepared SERS substrates.
\end{abstract}

Keywords: Raman spectroscopy, silver compound, Ag nanoparticle arrays, surfaceenhanced Raman scattering, pulsed laser deposition.

Manuscript received 15.09.14; revised version received 10.12.14; accepted for publication 19.02.15; published online 26.02.15.

\section{Introduction}

The silver nanoparticles (NPs) have a high efficiency at excitation of the local surface plasmon resonance, which has wide application in the surface-enhanced Raman scattering (SERS) of different analytes, photoluminescence of $\mathrm{Ge}$ and $\mathrm{Si}$ quantum dots, for creation of sensors and optoelectronic structures. The advantages of Ag NPs in comparison with Au ones are related with the high density of conduction electrons, favorable frequency dependence of complex dielectric permittivity in the visible spectral range and in absence of competition between plasmon and interband absorption. Unlike gold, the energy of interband $s p \rightarrow d$ transition in silver is located in the UV region of the spectrum. However, silver is unstable and subjected to oxidation with formation of compounds with oxygen, sulfur, carbon, nitrogen and chlorine [1]. It leads to complication in interpretation of Raman spectra when using SERS substrates with Ag NPs, because of localization of the characteristic bands inherent to silver compounds of the Ag NP shell in the frequency range 100 up to $1600 \mathrm{~cm}^{-1}$. Determination of the nature of these compounds is required to realize activation of SERS analytes, comprising choice of activator and analyte. Thereby, identification of oxidation products in Ag NP shell that are used for the SERS spectroscopy is an actual task.

Micro-Raman spectroscopy has seldom application in the role of initial analytic method for identification of chemical compounds on metal surface because of absence of the corresponding database of benchmark Raman spectra registered for the high-purity certified chemical compounds. In 2012, it was published the work in which, from the one hand, the short analysis of the Raman spectra of silver compounds prepared using different technologies in accord with literature data, was 
presented, and from the other hand, it was carried out the micro-Raman characterization of the certified silver compound powders: oxide $\left(\mathrm{Ag}_{2} \mathrm{O}\right)$, chloride $(\mathrm{AgCl})$, sulfide $\left(\mathrm{Ag}_{2} \mathrm{~S}\right)$, sulfite $\left(\mathrm{Ag}_{2} \mathrm{SO}_{3}\right)$, sulfate $\left(\mathrm{Ag}_{2} \mathrm{SO}_{4}\right)$, carbonate $\left(\mathrm{Ag}_{2} \mathrm{CO}_{3}\right)$, acetate $\left(\mathrm{AgC}_{2} \mathrm{H}_{3} \mathrm{O}_{2}\right)$, nitrate $\left(\mathrm{AgNO}_{3}\right)$ with the purity level higher than $99.99 \%$ [2]. As a result, it was proposed the catalogue of Raman spectra of the mentioned silver compounds, which allows characterization of silver oxidation processes.

Today a substantial amount of the works is devoted to Raman investigations, for example of the processes of chemical interaction of polycrystalline silver with $\mathrm{O}_{2}$, $\mathrm{H}_{2} \mathrm{O}, \mathrm{CO}_{2}$, ethylene, methanol [3], thermal dissociation of silver oxide [4], to study mechanisms of chemisorptions of oxygen on the silver analytic catalyzer [5], on the thermal-induced transformation of different silver oxides in the films of electrolytic silver [6], plasmon-active catalyzers of the reactions with $\mathrm{H}_{2}, \mathrm{O}_{2}$, $\mathrm{CO}$, hydro-carbonates based on $\mathrm{Ag} / \mathrm{AgO}_{\mathrm{x}} \mathrm{NPs}$ [7], etc. But due to characterization by different set of silver compounds of the investigation objects prepared under different technological conditions, using these Raman spectra is rather limited, although they also contain much important information.

For preparation of SERS substrates with Ag NPs, it was used many approaches including chemical, vacuum processes, electron-beam lithography, formation of various templates with colloid NPs, rough films, nanoparticle arrays including the organized ones. Especial interest is caused by forming the porous films with Ag NP arrays, because they are characterized by large internal surface for the analyte, possibility of formation in the pores the so-called "hot spots", spots with high values of local electro-magnetic fields that mostly provide the enhance in analyte Raman spectra. It is known about the porous nanocomposite systems in the form of porous glass-ceramics, porous layers of aluminum oxides, silicon prepared by anodization when the pore walls are covered with the films of silver (gold) [8-11]. It was formed the structures of porous gold from the $\mathrm{Au} / \mathrm{Ag}$ alloys by using the method of selective etching of silver [12].

In the literature, there are no information concerning production of the porous silver (por-Ag) films formed in vacuum and their application as a SERSsubstrates, also there are no data concerning Raman investigations of chemical compounds in the $\mathrm{Ag} \mathrm{NP}$ shell in por-Ag films.

Recently, the SERS-substrates based on films with Ag NP arrays were prepared using pulsed laser deposition (PLD) from the direct flux of erosion torch particles on the substrate located at some distance along the normal to the target plane [13]. Taking into account the advantages for the SERS substrates of porous films with Ag NP arrays, we have developed the corresponding PLD method that is different as compared to that in [13]. Deposition of Ag NPs is performed from the back low-energy flux of Ag particles on the substrate located in the target plane [14-16]. Under these conditions, it is possible to provide formation of silver chemical compounds in the Ag NP shell, which, correspondingly will affect the efficiency of SERS. Therefore, the aim of this work is identification, by using micro-Raman spectroscopy, of silver compounds of Ag NP shell that can be formed during preparation of the SERS substrates with nanocomposite porous films containing Ag NP arrays.

\section{Experimental}

Nanocomposite porous films (pores and Ag NPs) were prepared using the PLD method (see the insert to Fig. 1) from the back flux of the low-energy particles of erosion torch on the glass substrates located in the target plane (6). Nd:YAG laser radiation $\left(\lambda=1.06 \mu \mathrm{m}, \tau_{p}=10 \mathrm{~ns}, f_{p}=\right.$ $25 \mathrm{~Hz}$ ) with the energy in the pulse $200 \mathrm{~mJ}$ (1) was focused on the surface of silver target (5) that can move. Deposition was performed in the argon atmosphere under the pressure $P=10 \ldots 50 \mathrm{~Pa}(2)$. The density of the energy of laser pulse was about $j=5 \ldots 20 \mathrm{~J} / \mathrm{cm}^{2}$. The target irradiation time was varied from 1 up to 30 minutes, which corresponds to the change in the amount of pulses $N=1500 \ldots 45000$. Under the pulsed laser irradiation of the target, the erosion torch (4) is formed in the vacuum chamber. In the torch region, interaction of silver atoms between themselves and with gas atoms takes place, which is accompanied with creation of clusters and their deposition on the substrate with formation of structure of $\mathrm{Ag}$ NPs: $\mathrm{Ag}$-core/Ag compound shell. In the argon atmosphere, the cluster energy is scattered when colliding with atoms. The deposition regime provides preparation of porous films. Herewith, in the film regions located near the torch axis, it is deposited a larger amount of Ag NPs with larger sizes. With increasing the distance from the torch axis, a smaller amount of Ag NPs with smaller sizes is formed. Also, the porosity and thickness of the por-Ag film are changed as functions of the distance from the torch axis [14-16].

The thickness and the surface morphology of the por-Ag films were investigated by means of atomic force microscopy (AFM) using the Nanoscope IIIa scanning probe microscope operating in the taping mode. The silicon probes with the nominal radii of the tip apex close to $10 \mathrm{~nm}$ were used. Thickness variation of the por-Ag film along the sample was measured using the series of step height measurements. Sharp edged substrate-film steps were produced using the lift-off lithography process. The effective thickness of films at a given position was determined as a distance between centers of two maxima in the height histogram corresponding to the substrate and film levels. Investigation of the por-Ag films microstructure were also carried out using the scanning electron microscope (SEM) JSM-6490 LV (JEOL), with the energy-dispersed spectrometer [16] and using the transmission electron microscope (TEM) JEM-1011 (JEOL). 


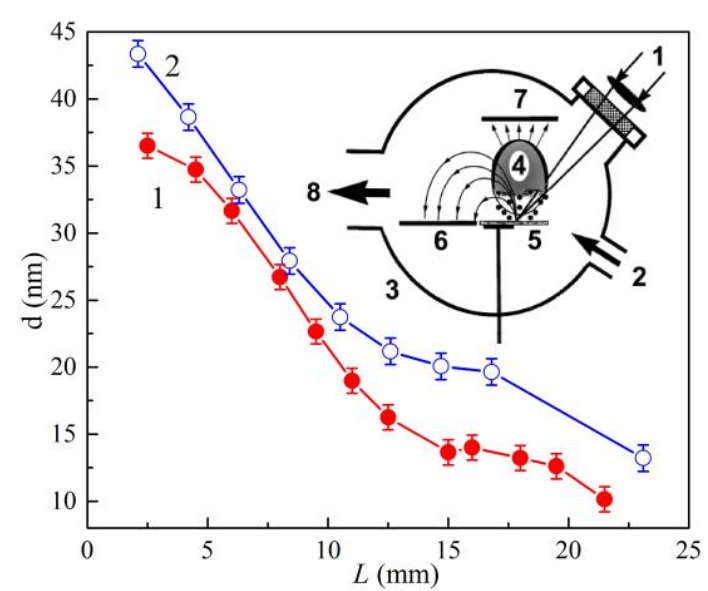

Fig. 1. Dependence of the thickness on the substrate coordinate $d(L)$ for por-Ag films prepared at $j=5 \mathrm{~J} / \mathrm{cm}^{2}, N=30000, P_{\mathrm{Ar}}$, Pa: $13.5(1), 20(2)$. In the insert - the scheme of the PLD vacuum set: 1 - laser beam, 2 - gas inflation, 3 - vacuum chamber, 4 - erosion torch, 5 - target, 6,7 - substrates, 8 - to the vacuum pump.

Transmission spectra of the films were registered with the spectrophotometer SF-26 in the wavelength range 340 up to $1200 \mathrm{~nm}$.

Micro-Raman spectra were measured using the triple spectrometer Horiba Jobin Yvon T64000 equipped with confocal optical microscope. As an optical excitation source, the $\mathrm{Ar}-\mathrm{Kr}$ laser line with $\lambda_{e x}=$ $488.0 \mathrm{~nm}$ was used. To prevent the photo-induced changes in silver compounds, the power of excitation laser radiation was reduced down to few milliwatts, the measuring time was equal to $100 \ldots 200 \mathrm{~s}$. The laser beam was focused on the sample surface in the spot with the diameter of about $0.7 \mu \mathrm{m}$. The spatial mapping of the optical spectra of studied structures was carried out via the automatic movement of the table with the step $0.1 \mu \mathrm{m}$. The accuracy of determination of the frequency of phonon bands was equal to $0.15 \mathrm{~cm}^{-1}$.

In this work, identification of silver chemical compounds in Ag NP shell in the por-Ag films by their vibrational bands in the Raman spectra was performed using the data of works [2-7]. The Raman spectra were mainly analyzed being based on comparison with the basic spectra presented in [2].

\section{Results and discussion}

In Fig. 1, being based on AFM measurements, it has been shown the dependence of the thickness $(d)$ of the por-Ag films as a function of the distance from the erosion torch axis $(L)$. The obtained profile of the thickness is similar to the wedge shape: at the increase of the distance from the torch axis, the films thickness decreases. The thickness of films was increased even with an insignificant increase of the argon pressure (compare curves 1 and 2 in Fig. 1).

With increasing the argon pressure, energy density, amount of pulses of target irradiation, the thickness of por-Ag films increases. In the mentioned range of formation conditions, the por-Ag film thickness lies within the values between 10 and $100 \mathrm{~nm}$.

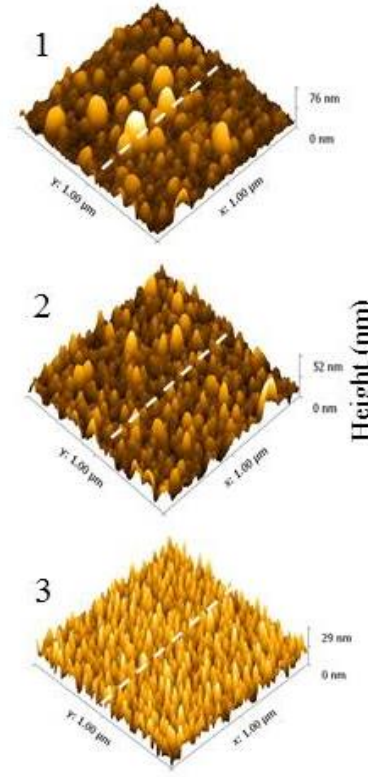

(a)

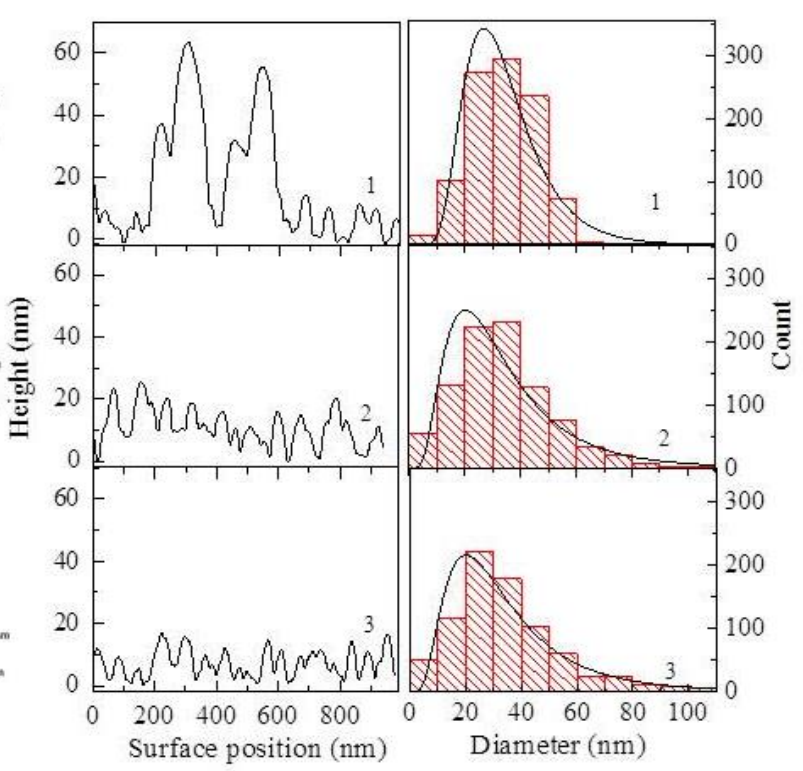

(c)

Fig. 2. (a) AFM image in the region of the por-Ag film on the distance from the erosion torch axis $L$, mm: 5 (1), 10 (2), 15 (3); (b) sectional (along the dashed line) analysis of the film and (c) histogram of distribution of the Ag NP sizes in these three regions of the wedge. 
In Fig. 2a, it was presented the AFM 3d-images of $1 \times 1 \mu \mathrm{m}$ por-Ag film deposited in the regime $j=$ $5 \mathrm{~J} / \mathrm{cm}^{2}, P=13.5 \mathrm{~Pa}, N=30000$ that are related to the substrate regions at various distances from the axis of erosion torch with different sizes of $\mathrm{Ag}-\mathrm{Nps}$ and pores. With increasing the distance from the erosion torch. Analysis of film surface morphology evidences about presence of Ag NPs and hollows between them in the same concentration. It was seen that the size of Ag NP and hollows decreases with increasing the distance from the erosion torch axis. In Fig. 2b, it was shown height profiles of the por-Ag film surface relief obtained along the dashed line for three regions of the wedge. One can see that the surface relief amplitude is substantially smaller in the region of por-Ag film with a smaller thickness (the longer distance from the torch axis). In Fig. 2c, the histograms of Ag NPs by the sizes (effective diameters) in dependence on the distance from the torch axis are presented. The size distribution shape transforms from the Gauss type to log-normal one, when the distance from the torch axis increases. The corresponding value of NPs diameters decreases from 35 down to $20 \mathrm{~nm}$. It should be noted that correlation between the thickness of film points and $\mathrm{Ag}$ NPs sizes takes place. The surface relief amplitude for the films has the same order of magnitude of their thickness. This evidence suggests greater porosity of por-Ag films.

Fig. 3a shows the SEM image of the por-Ag film on Si substrate. In the image, one can see light and dark spots of various shapes, which is indicative of the existence of Ag NPs, their conglomerates and surface pores in comparable concentrations. Fig. $3 \mathrm{~b}$ presents the TEM image of the por-Ag film. The corresponding histograms of distribution of Ag NPs by their sizes, obtained from the analysis of SEM and TEM images are shown in Figs. 3c and 3d. For the films with the smallest thickness, isolated spherical nanoparticles, i.e. island films, are typical. Using the method of X-ray dispersion spectroscopy, it was performed the elemental analysis of the por-Ag film deposited on the Si substrate (Fig. 3e) [16]. It was shown that, in the spectra except silver contained silicon (material of the $\mathrm{Si}$ substrate), carbon and oxygen in the Ag NP aggregates, it was additionally registered the less sulfur, chlorine and nitrogen. It is related with the fact that the concentration of the latter is lower than that of the oxygen and carbon atoms. The existence of carbon can be caused by uncontrolled contamination inserted in the process of por-Ag film deposition in the vacuum chamber by using the oil pump. Except this, oxygen is an impurity in argon and in silicon oxide on the used $\mathrm{Si}$ substrate. The value of the weight percents for uncontrolled impurities in the por$\mathrm{Ag}$ film determined from the X-ray spectrum are as follows: $\mathrm{C}-1.55 ; \mathrm{O}-1.48 ; \mathrm{Si}-73.58$ (substrate); $\mathrm{S}-$ $0.34 ; \mathrm{Cl}-0.46 ; \mathrm{Ag}-22.59$.

The transmission spectra, $T(\lambda)$, of the porous films with the Ag NP arrays prepared at various argon pressures are shown in Fig. 4. One can see the wide bands of plasmon absorption in the wavelength range 400 to $1000 \mathrm{~nm}$. At the increase of the argon pressure, the maximum shifts towards the long-wave region, the transmission value decreases, and the spectrum expands. This type of the spectra is caused by two reasons. First, with increasing the argon pressure the size of the torch decreases. It leads to enhancement of the interaction between silver atoms, the sizes of silver clusters in the torch increase, too. With larger sizes of silver clusters, the transmission spectra shift towards the more longwave region. Second, oxygen chemisorption, formation of the silver compounds with carbon in the shell of $\mathrm{Ag}$ NPs lead to the change in the dielectric permittivity of Ag NP shell and long-wave shift of the plasmon spectra [17]. Non-uniform expansion of the absorption band of the surface plasmon resonance is caused by dispersion of nanoparticle sizes and can be due to size-depending scattering of electrons at the surface, if the nanoparticle sizes become smaller than the average value of the free path for electrons in bulk metallic silver (of about $200 \mathrm{~nm})$ [18].

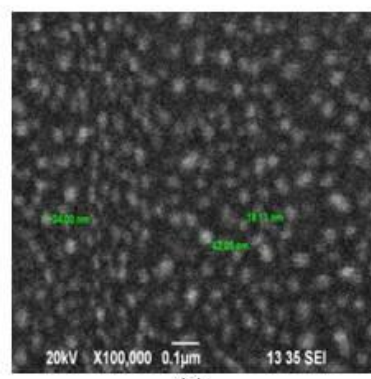

(a)

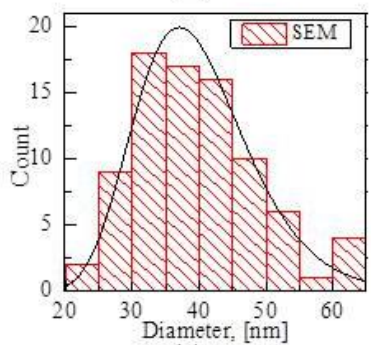

(c)

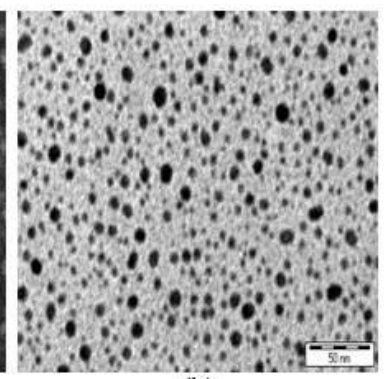

(b)

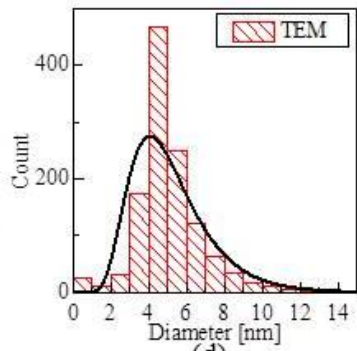

(d)

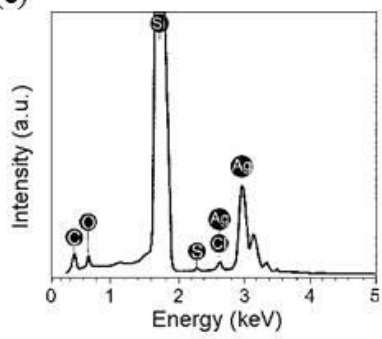

(e)

Fig. 3. (a) SEM image of por-Ag film $\left(j=5 \mathrm{~J} / \mathrm{cm}^{2}, N=30000\right.$, $\left.P_{\mathrm{Ar}}=13.5 \mathrm{~Pa}, L=5 \mathrm{~mm}\right)$; (b) TEM image of por-Ag film $(j=$ $5 \mathrm{~J} / \mathrm{cm}^{2}, N=1500, P_{\mathrm{Ar}}=13.5 \mathrm{~Pa}, L=15 \mathrm{~mm}$ ); (c), (d) the histograms of distribution of $\mathrm{Ag} \mathrm{NPs}$ by their sizes, correspondingly; (e) X-ray spectrum of por-Ag film from the left to right: carbon, oxygen, silicon, sulfur, chlorine, silver. 


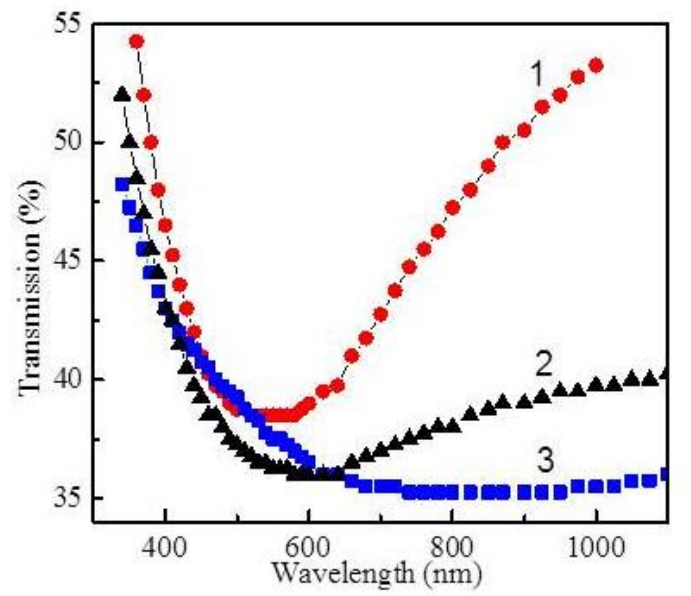

Fig. 4. Transmission spectra of por-Ag films prepared at $j=$ $5 \mathrm{~J} / \mathrm{cm}^{2}, N=15000, L=5 \mathrm{~mm}, P_{\mathrm{Ar}}, \mathrm{Pa}: 13.5$ (1), 20 (2), 50 (3).

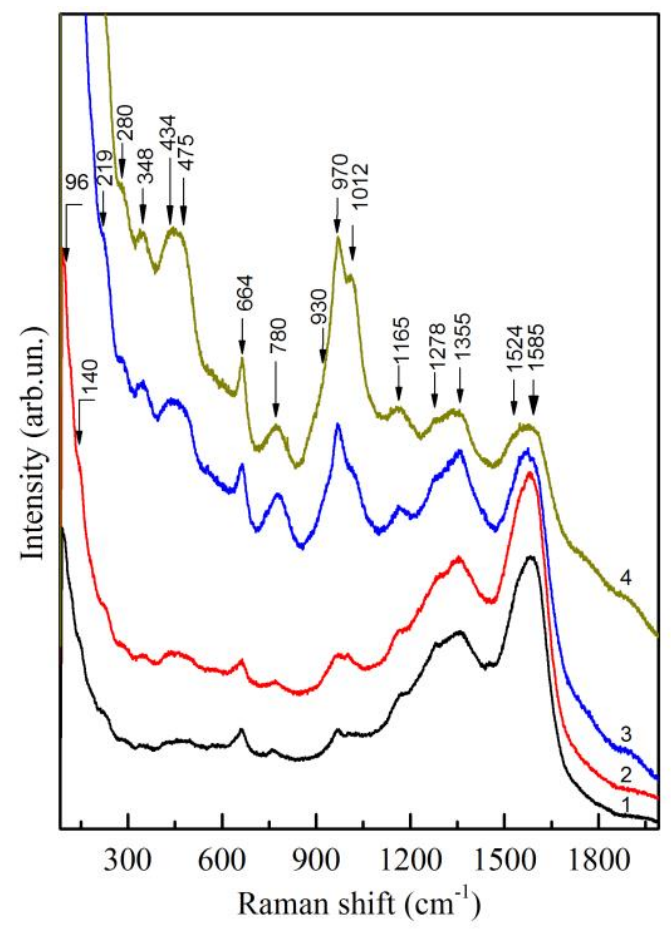

Fig. 5. Micro-Raman spectra of porous film with Ag NP arrays $\left(j=20 \mathrm{~J} / \mathrm{cm}^{2}, N=30000, P_{\mathrm{Ar}}=20 \mathrm{~Pa}\right)$ in the regions of the film at the distance from the erosion torch axis between $20 \mathrm{~mm}(1)$ to $5 \mathrm{~mm}(4)$

Fig. 5 shows the confocal micro-Raman spectra of the por-Ag nanocomposite film (pores and $\mathrm{Ag} \mathrm{NP}$ arrays) in its various regions along the direction from the erosion torch axis. In the Raman spectra, the following typical intense clear bands are registered in three spectral ranges: below $200 \mathrm{~cm}^{-1}\left(96,140 \mathrm{~cm}^{-1}\right)$, within the range 200 to $600 \mathrm{~cm}^{-1}$ - bands at 280,348,434, $475 \mathrm{~cm}^{-1}$, within the range 600 to $1800 \mathrm{~cm}^{-1}$ - band at $664 \mathrm{~cm}^{-1}$, wide band at $780 \mathrm{~cm}^{-1}$, band at $970 \mathrm{~cm}^{-1}$ with two shoulders at 933 and $1012 \mathrm{~cm}^{-1}$, wide bands at 1165 , $1355,1585 \mathrm{~cm}^{-1}$ with the shoulder at $1524 \mathrm{~cm}^{-1}$. The spectra obtained near and far from the axis of erosion torch are in general analogous, however, the intensities of different bands change substantially. In particular, the band intensity is larger from the regions that are near the axis of erosion torch, which is caused by a larger thickness of the por-Ag films as well as a larger content of silver oxidation products in Ag NP shell. The spectra obtained under changing of mentioned technological parameters are also analogous, the intensity of different bands changes inessentially. The possibility to observe the Raman spectra in the chemical compounds inside the shells of Ag NPs are associated with local surface plasmon resonance in Ag NP core.

Let us analyze the possible nature of the silver compounds that are formed in the process of por-Ag film deposition. The intense bands at $96,140 \mathrm{~cm}^{-1}$ are attributed to lattice vibrational modes of Ag NP cores. The analogous intense bands in the range below $200 \mathrm{~cm}^{-1}$ with equal to these values of the frequency were observed in numerous works, for example, for $\mathrm{Ag}_{2} \mathrm{O}\left(96,146 \mathrm{~cm}^{-1}\right)$, $\mathrm{Ag}_{2} \mathrm{CO}_{3}\left(106 \mathrm{~cm}^{-1}\right), \quad \mathrm{AgC}_{2} \mathrm{H}_{3} \mathrm{O}_{2} \quad\left(102 \mathrm{~cm}^{-1}\right.$ with the shoulder at $\left.140 \mathrm{~cm}^{-1}\right), \mathrm{Ag}_{2} \mathrm{~S}\left(93,147 \mathrm{~cm}^{-1}\right), \mathrm{Ag}_{2} \mathrm{SO}_{3}$ $\left(105 \mathrm{~cm}^{-1}\right.$ with the shoulder at $\left.144 \mathrm{~cm}^{-1}\right), \mathrm{AgNO}_{3}$ $\left(144 \mathrm{~cm}^{-1}\right.$ with the shoulders at 95 and $\left.158 \mathrm{~cm}^{-1}\right), \mathrm{AgCl}$ (95 $\mathrm{cm}^{-1}$ with the shoulders at 143 and $190 \mathrm{~cm}^{-1}$ ), and these bands are attributed to lattice vibrations of $\mathrm{Ag}$ [2].

Summarized in Table are the frequency positions of characteristic bands in the por-Ag films within the frequency range 200 to $1600 \mathrm{~cm}^{-1}$ from Fig. 5, and, for comparison, there were selected the most intense and characteristic (bench mark) bands for the expected silver compounds [2-7].

The wide bands with the clear maxima within the frequency range 200 to $600 \mathrm{~cm}^{-1}[2,5]$ :

- for $\mathrm{Ag}_{2} \mathrm{O}\left(230\right.$ - 248, 342, 430, 487, $\left.565 \mathrm{~cm}^{-1}\right)$ are caused by $\mathrm{Ag}-\mathrm{O}$ valence bending vibrations, moreover, the bands at 430 and $487 \mathrm{~cm}^{-1}$ are attributed to the tensile vibrations of the bulk $\mathrm{Ag}_{2} \mathrm{O}$ compound;

- for $\mathrm{Ag}_{2} \mathrm{CO}_{3}\left(204 \mathrm{~cm}^{-1}\right.$, the intense band is attributed to $\mathrm{Ag}-\mathrm{C}$ valence vibrations), for $\mathrm{AgC}_{2} \mathrm{H}_{3} \mathrm{O}_{2}\left(258 \mathrm{~cm}^{-1}\right.$, very intense band - $\mathrm{C}-\mathrm{O}-\mathrm{Ag}$ bending modes);

- for $\mathrm{Ag}_{2} \mathrm{~S}\left(243 \mathrm{~cm}^{-1}\right.$, shoulder at $273 \mathrm{~cm}^{-1}-\mathrm{Ag}-\mathrm{S}$ valence vibrations), for $\mathrm{Ag}_{2} \mathrm{SO}_{3}\left(460 \mathrm{~cm}^{-1}-\mathrm{O}-\mathrm{S}-\mathrm{O}\right.$ symmetric bending vibrations (swinging)), $\left(602 \mathrm{~cm}^{-1}-\mathrm{O}-\mathrm{S}-\mathrm{O}\right.$ asymmetric bending vibrations (torsional)), for $\mathrm{Ag}_{2} \mathrm{SO}_{4}$ (432, 460, $623 \mathrm{~cm}^{-1}-$ $\mathrm{O}-\mathrm{S}-\mathrm{O}$ symmetric (asymmetric) bending vibrations (swinging, torsional));

- for $\mathrm{AgCl}\left(233,345,409 \mathrm{~cm}^{-1}, \mathrm{Ag}-\mathrm{Cl}\right.$ valence vibrations).

Within the spectral range 200 to $600 \mathrm{~cm}^{-1}$, it is the most evident that the bands of the chemical compounds of silver with oxygen, carbon, chlorine, and among the compounds with sulfur, the most intense band is only for $\mathrm{Ag}_{2} \mathrm{~S}$; there are no bands in the Raman spectrum of $\mathrm{AgNO}_{3}$. 
Table. The comparison of the measured Raman spectrum of por-Ag films within the range $200-1600 \mathrm{~cm}^{-1}$ with the database for the Raman scattering in the silver compounds.

\begin{tabular}{|c|c|c|c|c|c|c|c|}
\hline por-Ag & $\operatorname{Ag}_{2} \mathrm{O}$ & $\mathrm{AgCl}$ & $\mathrm{Ag}_{2} \mathrm{CO}_{3}$ & $\mathrm{AgC}_{2} \mathrm{H}_{3} \mathrm{O}_{2}$ & $\operatorname{Ag}_{2} \mathrm{~S}$ & $\begin{array}{c}\mathrm{Ag}_{2} \mathrm{SO}_{3} \\
\left(\mathrm{Ag}_{2} \mathrm{SO}_{4}\right)\end{array}$ & $\mathrm{AgNO}_{3}$ \\
\hline 280 & $230-248$ & $233 \mathrm{~s}$ & $\begin{array}{l}204 \mathrm{~s}, \\
283 \mathrm{w}\end{array}$ & $258 \mathrm{vs}$ & $\begin{array}{l}243 \mathrm{vs}, \\
273 \mathrm{sh}\end{array}$ & & \\
\hline $348 \mathrm{~s}$ & 342 & $345 \mathrm{w}$ & & $341 \mathrm{sh}$ & & & \\
\hline $434-475 \mathrm{~s}$ & $\begin{array}{l}430, \\
487 \mathrm{~s}\end{array}$ & $409 \mathrm{vw}$ & & $490 \mathrm{w}$ & & $\begin{array}{c}460 \\
(432-480) \mathrm{w}\end{array}$ & \\
\hline $664 \mathrm{vs}$ & $565 \mathrm{~s}$ & & & $614 \mathrm{w}, 664$ & & $\begin{array}{c}602 \\
(595,623) \mathrm{w} \\
\end{array}$ & $698 \mathrm{vw}$ \\
\hline 780 & & & $\begin{array}{c}732,804, \\
853 \mathrm{w}\end{array}$ & & & & $\begin{array}{c}717 \mathrm{vw}, \\
791 \mathrm{w}\end{array}$ \\
\hline $\begin{array}{c}\text { (933), } 970 \\
(1012) \mathrm{vs}\end{array}$ & $\begin{array}{c}933-950 \mathrm{~s}, \\
1072, \\
1100 \mathrm{vs}\end{array}$ & & $1075 \mathrm{w}$ & $\begin{array}{l}933 \mathrm{~s}, \\
1030 \mathrm{w}\end{array}$ & & $\begin{array}{c}964(970) \text { vs, } \\
1076(1079)\end{array}$ & 1030 vs \\
\hline $\begin{array}{c}1165,1278 \\
1355 \mathrm{~s}\end{array}$ & & & $1341 \mathrm{w}$ & $\begin{array}{l}1346, \\
1410 \mathrm{~s}\end{array}$ & & & $1330 \mathrm{vw}$ \\
\hline $1524-1585 \mathrm{vs}$ & & & $1507 \mathrm{w}$ & $1536 \mathrm{w}$ & & & \\
\hline
\end{tabular}

Letter symbols of the band intensities: vs - very strong; $\mathrm{s}$ - strong; $\mathrm{w}$ - weak; vw - very weak; sh - band shoulder; without any symbols - less clear.

Within the range 600 to $1800 \mathrm{~cm}^{-1}$ for $\mathrm{Ag}_{2} \mathrm{O}$, it is typical to observe the intense bands at $933-950,1072$, $1100 \mathrm{~cm}^{-1}$ that are caused by $\mathrm{Ag}-\mathrm{O}$ valence vibrations. In the spectra of $\mathrm{AgC}_{2} \mathrm{H}_{3} \mathrm{O}_{2}$, it was observed the clear maxima at $933 \mathrm{~cm}^{-1}\left(\mathrm{C}-\mathrm{CH}_{3}\right.$ symmetric bending (swinging) vibrations), at $1410 \mathrm{~cm}^{-1}\left(\mathrm{CH}_{3}\right.$ symmetric bending vibrations), and more weak, as compared with the latter, vibrational bands at 1346, $1536 \mathrm{~cm}^{-1}$ (symmetric, asymmetric valence vibrations). For $\mathrm{AgNO}_{3}$, typical is the very intense phonon band at $1030 \mathrm{~cm}^{-1}(\mathrm{~N}-\mathrm{O}$ symmetric valence vibrations) and more weak bands at 690,717 , $1330 \mathrm{~cm}^{-1}$ (N-O bending (valence) vibrations). For $\mathrm{Ag}_{2} \mathrm{SO}_{3}\left(\mathrm{Ag}_{2} \mathrm{SO}_{4}\right)$, the spectra are very similar: very intense bands at $964\left(970 \mathrm{~cm}^{-1}\right)$ and at $1078\left(1079 \mathrm{~cm}^{-1}\right)$, which are caused correspondingly by $\mathrm{S}-\mathrm{O}$ symmetric and asymmetric valence vibrations. For the compounds $\mathrm{AgCl}, \mathrm{Ag}_{2} \mathrm{~S}$, the vibrational bands are absent within this range of Raman spectrum.

The performed analysis of the Raman spectra of silver chemical compounds using the literature data caused the choice of the benchmark bands that were presented in Table. Table information obtained using the method of comparison of the obtained spectrum of por$\mathrm{Ag}$ films and selected benchmark spectra of silver chemical compounds allow determining the possible nature of vibrations in the measured Raman spectra.

From Table, one can see that the band at $280 \mathrm{~cm}^{-1}$ can indicate the existence of silver compounds with oxygen, carbon, hydrogen, chlorine and sulfur as $\mathrm{Ag}_{2} \mathrm{~S}$ in the Ag NP shells. The band at $348 \mathrm{~cm}^{-1}$ was registered in the compounds of silver with oxygen, carbon, hydrogen and chlorine. The band at $434-475 \mathrm{~cm}^{-1}$ quite often is attributed to the vibrations of $\mathrm{Ag}_{2} \mathrm{O}$, in other cases it can be caused by the vibrations in compounds $\mathrm{AgCl}, \mathrm{AgC}_{2} \mathrm{H}_{3} \mathrm{O}_{2}$ and $\mathrm{Ag}_{2} \mathrm{SO}_{3}\left(\mathrm{Ag}_{2} \mathrm{SO}_{4}\right)$. The most probable nature of the registered bands at $624 \mathrm{~cm}^{-1}$ is the compounds of silver with oxygen, carbon $\left(\mathrm{AgC}_{2} \mathrm{H}_{3} \mathrm{O}_{2}\right)$, $\mathrm{Ag}_{2} \mathrm{SO}_{3}\left(\mathrm{Ag}_{2} \mathrm{SO}_{4}\right)$ and $\mathrm{AgNO}_{3}$, and for the band at
$780 \mathrm{~cm}^{-1}$ - vibrations in $\mathrm{Ag}_{2} \mathrm{CO}_{3}$ and $\mathrm{AgNO}_{3}$. The strong bands at $970 \mathrm{~cm}^{-1}$ with the shoulders at 932 and $1012 \mathrm{~cm}^{-1}$ are caused by manifestation of the compounds of silver with oxygen, carbon $\left(\mathrm{AgC}_{2} \mathrm{H}_{3} \mathrm{O}_{2}\right)$, sulfur $\left(\mathrm{Ag}_{2} \mathrm{SO}_{3}, \mathrm{Ag}_{2} \mathrm{SO}_{4}\right)$ and nitrogen. The strong bands observed at $1355,1524-1585 \mathrm{~cm}^{-1}$ are caused by the compound of silver with carbon $\left(\mathrm{Ag}_{2} \mathrm{CO}_{3}, \mathrm{AgC}_{2} \mathrm{H}_{3} \mathrm{O}_{2}\right)$. Thus, according to micro-Raman spectroscopy the main composition of shells on Ag NPs are silver compounds with oxygen and carbon. It is noteworthy that the revealed nature of the shells in Ag NPs, in the view of mentioned compounds, coincides with $\mathrm{X}$-ray spectral data (see Fig. 3e).

The determined nature of Ag NPs shells, their manifestation in the micro-Raman spectra allow, firstly, to exclude some difficulties in interpretation of the SERS spectra of analytes when controlling the technology of preparation of the films with Ag NPs arrays. Secondly, determination of chemical composition inherent to the shells compounds of Ag NPs promotes developing the more efficient SERS substrates by controlling the processes of preparation of por-Ag films as well as by selecting SERS activators and analytes.

\section{Conclusions}

Developed in this work is the method for preparation of nanocomposite porous films with silver nanoparticle arrays by using pulsed laser deposition from the back flux of the erosion torch particles. The optimal conditions of por-Ag film formation with the gradient change in its thickness and sizes of Ag NPs as well as pores have been determined. It has been investigated the peculiarities of the absorption spectra that are related to local surface plasmon resonance of Ag NPs. Using the method of confocal micro-Raman spectroscopy, it has been investigated the nature of the silver chemical compounds in the silver nanoparticle shells in por-Ag

\section{(C) 2015, V. Lashkaryov Institute of Semiconductor Physics, National Academy of Sciences of Ukraine}


films. The bands in the Raman spectra at 96 and $140 \mathrm{~cm}^{-1}$ are caused by lattice vibrational modes of Ag-core NPs. The registered Raman bands at 280, 348, 434-475, 664, $780,970 \mathrm{~cm}^{-1}$ and at $1165-1355,1524-1585 \mathrm{~cm}^{-1}$ are predominantly related to the compounds of silver with oxygen and carbon. The obtained results will be used for interpretation of the vibrational spectra of analytes placed on the prepared SERS substrates.

\section{References}

1. E. Le Ru, P. Etchegoin, Principles of Surface Enhanced Raman Spectroscopy and Related Plasmonic Effects, first ed. Elsevier, Amsterdam, 2009.

2. I. Martina, R. Wiesinger, D. Sembrih-Simbürger, M. Schreiner, Micro-Raman characterization of silver corrosion products: Instrumental set up and reference database // Raman Spectroscopy, 9, p. 1-8 (2012).

3. Chuan-Bao Wang, G. Deo, I.E. Wachs, Interaction of polycrystalline silver with oxygen, water, carbon dioxide, ethylene, and methanol: in situ Raman and catalytic studies // J. Phys. Chem. B, 103, p. 56455656 (1999).

4. G.I.N. Waterhouse, G.A. Bowmaker, J.B. Metson, The thermal decomposition of silver (I, III) oxide: A combined XRD, FT-IR and Raman spectroscopic study // Phys. Chem. Chem. Phys. 3, p. 3838-3845 (2001).

5. G.I.N. Waterhouse, G.A. Bowmaker, J.B. Metson, Mechanism and active sites for the partial oxidation of methanol to formaldehyde over an electrolytic silver catalyst // Applied Catalysis A: General, 265, p. 85-101 (2004).

6. R. Liping, D. Weilin, Y. Xinli, C. Yong, X. Zaiku, F. Kangnian, Transformation of various oxygen species on the surface of electrolytic silver characterized by in situ Raman spectroscopy // Chin. J. Catal. 27(2), p. 115-118 (2006).

7. Z. Zhao, M.A. Carpenter, Support-free bimodal distribution of plasmonically active $\mathrm{Ag} / \mathrm{AgO}_{\mathrm{x}}$ nanoparticle catalysts: attributes and plasmon enhanced surface chemistry // J. Phys. Chem. C, 117(21), p. 11124-11132 (2013).

8. Z. Pan, A. Zabalin, A. Veda, M. Guo, M. Groza, A. Burger, R. Mu, S.H. Morgan, Surface-enhanced Raman spectroscopy using silver-coated porous glass-ceramic substrates // Applied Spectroscopy, 59(6), p. 782-786 (2005).
9. S. Chan, S. Kwon, T-W. Koo, L.P. Lee, A.A. Berlin, Surface-enhanced Raman scattering of small molecules from silver-coated silicon nanopores // Adv. Mater. 75(19), p. 1595-1598 (2003).

10. S.N. Terekhov, P. Mojzes, S.M. Kachan et al., A comparative study of surface-enhanced Raman scattering from silver-coated anodic aluminum oxide and porous silicon // Raman Spectroscopy, 42, p. 12-20 (2011).

11. K. Grytsenko, Yu. Kolomzarov, O. Lytvyn, T. Doroshenko, V. Strelchuk, SERS of dye film deposited onto gold nano-clusters // Semiconductor Physics, Quantum Electronics \& Optoelectronics, 13(2), p. 151-153 (2010).

12. L.H. Qian, X.Q. Yan, T. Fujita et al., Surface enhanced Raman scattering of nanoporous gold: Smaller pore sizes stronger enhancements // Appl. Phys. Lett. 90, p. 153120 (1-3) (2007).

13. C.A. Smyth, I. Mirza, J.G. Junney, E.M. Mc Cabe, Surface-enhanced Raman spectroscopy (SERS) using Ag nanoparticle films produced by pulsed laser deposition // Appl. Surf. Sci. 264, p. 31-35 (2013).

14. E.B. Kaganovich, S.A. Kravchenko, L.S. Maksimenko et al., Polarization properties of porous gold and silver films // Optics and Spectroscopy, 110(4), p. 513-521 (2011).

15. E.G. Manoilov, Optical and photoluminescence properties of $\mathrm{Ag} / \mathrm{Al}_{2} \mathrm{O}_{3}$ nanocomposite films obtained by pulsed laser deposition // Semiconductor Physics, Quantum Electronics \& Optoelectronics, 12(2) p. 298-301 (2009).

16. E.B. Kaganovich, I.M. Krishchenko, E.G. Manoilov, N.P. Maslak-Gudyma, V.V. Kremenitskiy, Structure and optical properties of gold and silver porous films obtained by pulsed laser deposition in vacuum // Nanosystems, Nanomaterials, Nanotechnologies, 10(4), p. 859-868 (2012).

17. A.D. Mc Farland, R.P. Van Duyne, Single silver nanoparticles as real-time optical sensors with zeptomole sensitivity // NanoLett. 3(8), p. 1057 (2003).

18. S. Hayashi, R. Koga, M. Ohtuji, K. Yamamoto, and M. Fujii, Surface plasmon resonances in gasevaporated Ag small particles: Effects of aggregation // Solid State Communs. 76, p. 1067 (1990). 